\title{
An Alternate Natural Remedy for Symptomatic Relief of Helicobacter pylori Dyspepsia
}

\author{
Abdullah M Nasrat ${ }^{1^{*}}$, Salwa AM Nasrat ${ }^{2}$, Randa M Nasrat ${ }^{3}$ and Mohammad M Nasrat ${ }^{4}$ \\ ${ }^{1}$ Department of Surgery, Balghsoon Clinic, Jeddah, KSA \\ ${ }^{2}$ Department of Physical Therapy, Cardiac Surgery Academy, Cairo, Egypt \\ ${ }^{3}$ Department of Internal Medicine, Helwan General Hospital, Helwan, Egypt \\ ${ }^{4}$ Department of Internal Medicine, Helwan General Hospital, Helwan, Egypt
}

*Corresponding author: Abdullah M Nasrat, Department of Surgery, Balghsoon Clinic, Jeddah, PO Box 5261, KSA-21573; Tel: + 966 (012) 667 3645; E-mail: abdullahalnasrat@yahoo.com

Rec date: June 25, 2015 Acc date: July 22, 2015 Pub date: July 30, 2015

Copyright: @ 2015 Nasrat AM, et al. This is an open-access article distributed under the terms of the Creative Commons Attribution License, which permits unrestricted use, distribution, and reproduction in any medium, provided the original author and source are credited.

\begin{abstract}
Aim: This study aimed at introducing a simple natural remedy for adequate clinical symptomatic relief of Helicobacter pylori dyspepsia.

Background: Helicobacter pylori remains a challenging worldwide medical problem due to its extreme widespread prevalence, the lost quality of life of patients, the economic burden associated with its upper gastrointestinal symptoms and its close relation to acid peptic disease, gastric carcinoma and lymphoma. A massive knowledge has lately evolved concerning rediscovery and treatment of $H$. pylori; in fact, most of this information is exceedingly in need of re-assessment and redetermination. As acetate exists among the end products in the metabolism of $H$. pylori; therefore, vinegar could interfere with the energy metabolism and the respiratory chain of the bacterium according to the rules of feedback regulation and product inhibition.
\end{abstract}

Patients and Methods: 100 Patients were included in this study according to their clinical symptoms and serology testing. Their age ranged between 35-50 years, 11 patients were newly diagnosed. All were given a vinegar-mixed food or salad during meals for 10 days.

Results: 90 patients showed complete disappearance of their clinical symptoms. 7 patients showed incomplete relief of symptoms; their symptoms were relieved after revision of treatment. Recurrence occurred in 3 patients which were easily treated. Disappearance of clinical symptom was considered a clinical cure of symptoms with no need for further testing.

Conclusion: The natural remedy used in this study, acetic acid (dietary vinegar), proved to be simple, costless and effective, even the relief of clinical symptoms was immediate and rather dramatic. It constitutes a simple and decisive solution for the economic burden and the lost patient's quality of life caused by $H$. pylori.

Keywords: Helicobacter pylori; Mucosa associated lymphoid tissue; Atrophic gastritis

\section{Introduction}

Functional dyspepsia is a clinical syndrome defined as chronic or recurrent pain or discomfort in the upper abdomen of a variable origin. A general agreement exists on the irrelevant role played by Helicobacter pylori in the pathophysiology of functional dyspepsia [1]. $H$. pylori represents one of the most common and medically prominent infections worldwide; it is becoming exceedingly a challenging medical problem. About $50 \%$ of adults in the developed and $80-90 \%$ in the developing countries are estimated to be infected by H. pylori $[2,3]$.

Infection with $H$. pylori is typically life-long unless treated. It has got a clear age-related prevalence; increasing from $10 \%$ in those younger than 30 until it reaches a plateau of about $60 \%$ in those older than age of 60 or even to about $70 \%$ at 50 years of age in higher risk areas $[4,5]$.

In children, infection starts trans-familial during early childhood, and the $H$. pylori strain is often identical with that of parents. Interestingly, children maintain the same strain genotype even after moving to a different environment [6].

H. pylori clearly causes histologic gastritis; the most common endpoint of $H$. pylori infection is chronic superficial gastritis which is a leading element of peptic ulcer disease. Although duodenal and gastric ulcers develop in the minority of $H$. pylori infected patients; yet, $H$. pylori infection is found in $80 \%$ to $95 \%$ of patients with duodenal ulcers and $70 \%$ to $90 \%$ of patients with gastric ulcers. The observation that eradication of $H$. pylori by antibacterial treatment results in normalization of the gastric histology and prevents the recurrence of peptic ulcers strongly supports the role of $H$. pylori in chronic gastritis and peptic ulcer disease [4]. 
Atrophic gastritis is a further end result of chronic gastritis; longterm atrophic changes with metaplasia predispose to and increase the risk of gastric carcinoma. H. pylori is classified as type I (definitive) carcinogen, and gastric cancer is considered the world's second cause of cancer-related mortality $[4,6]$.

The mucosal lymphocytic response to $H$. pylori infection significantly increases the risk of gastric mucosa associated lymphoid tissue (MALT) lymphoma as the vast majority of gastric MALT lymphoma patients are infected with $H$. pylori. Interestingly; both $H$. pylori and MALT lymphoma are so linked as if they were almost born simultaneously. The normal stomach is devoid of organized lymphoid tissue; it was shown that lymphocytic gastritis and lymphoid follicles develop in $H$. pylori infected persons in response to infection, and the formed lymphoid tissue is morphologically identical with normal MALT. Furthermore; it was found that eradication of $H$. pylori with antibiotics alone resulted in regression of gastric MALT lymphoma in $75 \%$ of patients, and those patients have shown sustained clinical remission of their lymphomas. The recent estimated incidence of this lymphoma in Europe is 7-8 per 100,000 population, and it could reach 13 per 100,000 population. Developing countries, not surprisingly, show higher incidences. Prolonged residual MALT lymphoma could constitute an additional risk for gastric carcinoma [6,7].

The economic burden associated with the gastrointestinal symptoms makes $H$. pylori-associated disorders an ideal subject for economic evaluation. Cost-effectiveness analysis should be understood as the overall improvement in the quality of health care services, and not simply a way to reduce health care costs. There has been an obvious controversy concerning the cost effectiveness of the management of $H$. pylori infection [8].

$H$. pylori infection can be detected by a variety of methods; the simplest and least expensive method is serology. Positive serology does not distinguish between active and chronic infection, and is less specific as compared to other methods like histopathology, culture, $H$. pylori faecal antigen or urea breath test [9]. In a study of empirical eradication of $H$. pylori based on cost-effectiveness analysis, serology was also found to be the best cost effective among diagnostic measures [10].

The efficacy of $H$. pylori eradication treatment for non-ulcer dyspepsia is also controversial, different randomized controlled trails have given conflicting results. Overall, $H$. pylori eradication treatment for non-ulcer dyspepsia had no significant effect on quality of life compared with placebo [11-13]. H. pylori eradication for non-ulcer dyspepsia symptoms was found more costly if compared to antacid treatment. However, it has been of small but statistically significant benefit for dyspepsia symptoms of non-ulcer patients; patients receiving eradication treatment would benefit by an average of an extra 0.56 months free from dyspepsia per year than those given antacid [14]. Further studies comparing between $H$. pylori treatment and eradication for non-ulcer dyspepsia showed improvement of dyspeptic symptoms after treatment or eradication with little differences between them [15].

Data from observational studies have proposed a protective role of $H$. pylori infection against the development of gastro-oesophageal reflux disease, and suggested that $H$. pylori eradication treatment may increase the incidence of reflux symptoms. It was observed that the prevalence of $H$. pylori infection has been decreasing in developed countries, while the prevalence of gastro-oesophageal reflux disease and oesophageal adenocarcinoma have been increasing since 1930s
[16-19]. A randomized controlled trial done in Sep 2000 did not report significant increase in reflux disease after $H$. pylori eradication, [14] while another study reported that eradication of $H$. pylori infection acts on the improvement of gastro-oesophageal disease [20].

Although the appropriate length of $H$. pylori treatment remains also controversial, yet most strategies suggest that eradication of $H$. pylori is more cost effective than conventional therapy for the treatment of gastric and duodenal ulcers [21,22]. Bacterial resistance and treatment failure would add further cost for eradication, and might render routine pretreatment sensitivity testing to become a cost effective measure in some situations [23].

In a further aspect, eradication of $H$. pylori infection was found potentially effective in reducing mortality from distal gastric cancer and peptic ulcer disease [22,24]. It has been estimated that 1:30-1:60 of the UK population die from an $H$. pylori related disease [25].

\section{Design and Setting}

Prospective study done in Balghsoon Clinics in Jeddah/Saudi Arabia during Oct. 2011- May 2013.

\section{Patients and Methods}

100 patients with frank dyspeptic symptoms were included in this study without any social or class selection, their age ranged between 35-50 years. 11 of them were newly diagnosed; diagnosis was based on clinical symptoms and serology. All patients were given a natural remedy for 10 days, the basic principle of this natural remedy was dietary white vinegar (acetic acid 5\%) given in 2 ways; one for gastric treatment, the other for oral treatment. The gastric treatment consisted of adding $15 \mathrm{cc}$ of dietary white vinegar to a food stuff (white cheese, yoghurt, mashed potato; best is yoghurt), and to be taken twice daily as a salad with lunch and dinner meals. The oral treatment was done to control gastric re-recurrence from dental plaque colonization; $5 \mathrm{cc}$ of white vinegar as mouth wash once daily for 2-3 days per week.

\section{Results}

Relief of gastric symptoms was immediate and it was expressed by some patients as being dramatic. Spontaneous disappearance of clinical symptoms was considered as clinical cure; it occurred in 90 patients between 7 and 10 days of treatment. Seven patients did not show complete disappearance of clinical symptoms until 10 days, relief of their clinical symptoms was accomplished by repetition of treatment.

Recurrence of symptoms occurred in 3 patients, possibly due recurrence via oral intake, which was easily managed by the natural remedy for less than 3 days. Only one patient in this series did not get rid of his symptoms after vinegar therapy; an associated gastric pathology unrelated to $H$. pylori needed to be properly assessed. Two patients did not complete the study.

None of the cured 97 patients showed any clinical symptoms of gastro-esophageal reflux.

\section{Ethical Considerations}

An informed signed consent was taken from all patients, they were made aware about safety of the natural remedy and they were free to quit the study whenever they like. All patients were allowed to lead 
their routine style of life except restriction of outside-home meals. The research proposal was approved and the study followed the rules of the Research Ethics Committee of King Faisal Specialized Hospital and Research Center in Jeddah, Saudi Arabia.

\section{Discussion}

H. pylori infection remains a challenging worldwide medical problem due to its extreme widespread prevalence, the lost quality of life of patients and the economic burden associated with its upper gastrointestinal symptoms $[6,26]$.

$H$. pylori infection is associated with chronic superficial gastritis, and there is unequivocal evidence that infection with $H$. pylori plays a principal role in the pathogenesis of peptic ulcer disease. Increasing evidences indicate that $H$. pylori is an important reason in causing gastric carcinoma and lymphoma $[4,14,27]$. All these reasons made the medical world believe that $H$. pylori eradication should be a necessary attempt.

Although the eradication regimens efficiently eradiate $H$. pylori from the stomach; the emergence of antibiotic-resistant $H$. pylori strains, the severe side effects and high costs are major drawbacks of these treatments [28]. More efficient, economic and friendly drugs need to be developed.

Amazingly; $H$. pylori may not be just a bad bug in all instances, as complete eradication of the bacterium might introduce new problems due to the low gastric acidity. H. pylori has been shown to be a protective agent against low $\mathrm{pH}$ level-related carcinomas involving the cardia of the stomach; [6] what a challenge!! As if a medicine is needed to eradicate $H$. pylori and to avoid the side effects of the treatment itself at the mean time.

Cost effectiveness should be an integral element in selecting an eradication strategy for $H$. pylori; small differences in efficiency of different strategies can affect the comparative cost of eradication [29]. The efficacy of $H$. pylori eradication strategies, the appropriate length of treatment and the cost effectiveness, all appear controversial $[15,22]$

Antibiotic-resistant $H$. pylori strains are becoming increasingly prevalent; treatment failure would add further cost and burden as most physicians currently treat $H$. pylori without relying on antimicrobial susceptibility testing to choose the best effective regimen [23]. Furthermore, treatment that does not eradicate $H$. pylori is associated with rapid recurrence of acid-peptic disease in most patients [30].

Some reports suggested empirical eradication of $H$. pylori or treat approach rather than test-and-treat approach to improve the cost effectiveness of eradication among patients of already diagnosed noncomplicated duodenal ulcer [10,31].

The mechanism by which $H$. pylori eradication reduces dyspepsia symptoms in patients with non-ulcer dyspepsia is unclear [4]. It is also uncertain whether $H$. pylori augments the antisecretory effects of proton pump inhibitors or it accelerates the development of atrophic gastritis; therefore, the conflicting data indicating that reflux symptoms or erosive oesophagitis develop after $H$. pylori eradication should not be overlooked. Moreover, the high prevalence of mild body atrophic gastritis in $H$. pylori positive patients suggests that $H$. pylori eradication is unlikely to lead to gastric functional recovery $[18,32]$.

All these arguments related to the challenges caused by $H$. pylori and its management have raised up the motive for this study aiming at introducing a reliable simple choice that can give sufficient relief of clinical symptoms and an adequate cure with minimal cost.

Concerning the clinical picture of $H$. pylori; acute infection includes upper gastrointestinal pain, burping, gastric distension, halitosis, hyperacidity and later hypochlohydria, while chronic infection can be asymptomatic. Gastric acid secretion is stimulated during early stages by the inflammatory process and by the juxtamucosal ammonia produced by the bacterium, while hypochlorhydria develops later due to mucosal atrophy $[27,33]$. In this study, patients were included according to their clinical symptoms and serology testing. Serology, though non-specific as regards $H$. pylori detection, yet it was chosen as being simple and costly effective $[9,10]$

Concerning the pathologic behavior, $H$. pylori colonized the stomach since an immemorial time; [6] as if both the stomach and the bacterium used to live together in peace harmless to each other.

The organism resides and colonizes under the layer of mucus overlying gastric mucosa; colonization rates increase with age that could reach $50 \%$ in an asymptomatic adult over 50 years of age. The organism's intense urease activity produces ammonia from organic urea in gastric juice in such amounts that can buffer the $\mathrm{pH}$ of gastric acid. Although gastric acid plays an important role in the protection against many enteric organisms, and $H$. pylori can be readily killed by a brief exposure to hydrochloric acid solutions with $\mathrm{pH}$ below 4.0; yet, survival of $H$. pylori inside the stomach is achieved through various defense mechanisms. The gastric mucus layer is relatively thick and viscous allowing for $H$. pylori $\mathrm{pH}$ gradients from approximately $\mathrm{pH} 2$ close to the gastric lumen until $\mathrm{pH} 7.4$ immediately adjacent to the mucosa. The high motility of $H$. pylori via its flagellae even in very viscous mucus allows the organism to swim and migrate freely to reach the most favourable $\mathrm{pH}$ gradient. Furthermore, elaboration of ammonia from endogenous urea buffers gastric acid in the immediate vicinity of the organism [27,32-35].

In vitro inhibition of $H$. pylori growth was demonstrated due to the effect of $\mathrm{pH}$ of bio-organic acids, lactic and acetic, with the lactic acid demonstrating the greatest inhibition [36] In an interesting case report, discontinuation of vinegar and lemon intake was associated with the development of $H$. pylori infection in a 52 years old male adapted to high daily intake of acid substances [37].

The complex nutritional requirements of $H$. pylori are achieved via its unique energy metabolism, which exhibits characteristic dislocation sites. These sites can be considered as targets that should attract any attempts to fight the organism $[28,38]$. As acetate is demonstrated as an end product among the metabolic pathway of $H$. pylori; $[39,40]$ therefore, addition of acetic acid in the atmosphere around $H$. pylori could compromise the energy metabolism of $H$. pylori or interfere with the organism's respiratory chain metabolism. This suggestion is supported by the fact that the major routes of generation of energy for $H$. pylori are via pyruvate and the activity of the pyruvate dehydrogenase complex is controlled by the rules of product inhibition and feedback regulation [41,42] For the same reason, addition of pyruvate to different solid culture media was found to inhibit bacterial growth, and this inhibition was attributed to accumulation of acetate and formate [43].

The main product of glucose utilization of $H$. pylori was identified as lactate [38] therefore, yoghurt was chosen in this study as the best food stuff to be mixed with vinegar in order to assist interference with the energy metabolism of the organism through product inhibition. 
Page 4 of 5

As the matter includes interference with the energy metabolism and the respiratory chain metabolism of $H$. pylori; an immediate paralysis of the bacterium could be considered, which explains the immediate symptomatic relief expressed by some patients upon intake of a vinegar-mixed food.

It has been reported that the disappearance of dyspeptic symptoms can be an indication of clinical cure; patients who are rendered asymptomatic after treatment do not need further investigation or treatment, they can just return for re-assessment if they develop recurrent symptoms [44]. It has been reported that, in patients with uncomplicated duodenal ulcer, evaluation of eradication after $H$. pylori treatment markedly increases cost with no clear improvement in results; and therefore evaluation should not be performed routinely [45]. In this study, eradication of clinical symptoms was considered a clinical cure. Recurrence of symptoms in this study was negligible, and was treated by returning to the natural remedy for few days; 3-5 days.

Concerning oral eradication, mouth wash with dietary white vinegar was the method in this study to deal with the dental plaque colonization in order to prevent gastric recurrence.. Dental plaques being a secondary reservoir for $H$. pylori can lead to gastric reinfection. In a study done in March 2003, gastric eradication was achieved in $83 \%$ of patients, while efforts to eradicate dental plaque colonization were unsuccessful in all patients [46].

The fact that vinegar has got an antibacterial activity that can induce immediate in vitro inhibition of the growth of pathogenic bacteria allowing its use in different practical applications, has been reported in literature $[36,47]$. It has been also reported that bacterial growth on fish fillets media was highly inhibited by relatively small concentrations of acetate (less than 0.3\%) [48].These facts strongly support the idea of using vinegar for hands disinfection to control fecal-oral re-infection in patients under $H$. pylori eradication therapy.

H. pylori re-infection; whether it is gastric recurrence from dental plaques, fecal-oral re-infection or re-infection via oral intake, is hardly avoidable. In children, elimination of $H$. pylori is probably common due to the frequent antibiotic use for other reasons; yet, trans-familial recurrence still resembles a challenge. Moreover, tonsils and adenoids are lately discovered as secondary reservoirs for $H$. pylori in children $[6,49]$.

The previous three decades have shown evolution of massive knowledge concerning the subject of $H$. pylori; specifically after the rediscovery of a bacterium which is surviving in the stomach and the development of $H$. pylori antibiotic eradication therapies in 1985 \& 1986. In fact, most of these scientific criteria are exceedingly in need of extensive re-assessment and accurate redetermination [50].

\section{Conclusion}

The natural remedy (dietary vinegar) used in this study constitutes a simple answer for a complex subject; it proved to be simple, costless and effective. Moreover, it does not deprive the stomach form the useful bactericidal effect of gastric $\mathrm{HCl}$ and it does not carry the disadvantage of increased gastro-esophageal reflux symptoms. It is worthy of wide practical application and changing the attitude towards the challenge known as $H$. pylori dyspepsia.

\section{References}

1. Stanghellini V, De Ponti F, De Giorgio R, Barbara G, Tosetti C, et al. (2003) New developments in the treatment of functional dyspepsia. Drugs 63: 869-892.

2. Versalovic J (2003) Helicobacter pylori. Pathology and diagnostic strategies. Am J Clin Pathol 119: 403-412.

3. Strnad M, Presecki V, Babus V (2002) Epidemiology of Helicobacter pylori infection. Lijec Vjesn 124: 5-9.

4. Andreoli TE (2001) Cecil Essentials of Medicine. WB Saunders Company 5: 334 .

5. Asaka M (2003) [Epidemiology of Helicobacter pylori infection in Japan]. Nihon Rinsho 61: 19-24.

6. Farinha P, Gascoyne RD (2005) Helicobacter pylori and MALT lymphoma. Gastroenterology 128: 1579-1605.

7. Copie-Bergman C, Locher C, Levy M, Chaumette MT, Haioun C, et al. (2005) Metachronous gastric MALT lymphoma and early gastric cancer: is residual lymphoma a risk factor for the development of gastric carcinoma? Ann Oncol 16: 1232-1236.

8. Fendrick AM (2000) The role of economic evaluation in the diagnosis and treatment of Helicobacter pylori infection. Gastroenterol Clin North Am 29: 837-851.

9. Taj Y, Essa F, Kazmi SU, Abdullah E (2003) Sensitivity and specificity of various diagnostic tests in the detection of Helicobacter pylori. J Coll Physicians Surg Pak 13: 90-93.

10. García-Altés A, Jovell AJ, Serra-Prat M, Aymerich M (2000) Management of Helicobacter pylori in duodenal ulcer: a costeffectiveness analysis. Aliment Pharmacol Ther 14: 1631-1638.

11. McColl K, Murray L, El-Omar E, Dickson A, El-Nujumi A, et al. (1998) Symptomatic benefit from eradicating Helicobacter pylori infection in patients with nonulcer dyspepsia. N Engl J Med 339: 1869-1874.

12. Blum AL, Talley NJ, O'Moráin C, van Zanten SV, Labenz J, et al. (1998) Lack of effect of treating Helicobacter pylori infection in patients with nonulcer dyspepsia. Omeprazole plus Clarithromycin and Amoxicillin Effect One Year after Treatment (OCAY) Study Group. N Engl J Med 339: 1875-1881.

13. Talley NJ, Janssens J, Lauritsen K (2001) Eradication of Helicobacter pylori in functional dyspepsia : a randomised double blind placebo controlled trial with 12 months follow up. The Optimal Regimen Cures Helicobacter Induced Dyspepsia (ORCHID) Study Group. BMJ 318: 833-837.

14. Moayyedi P, Soo S, Deeks J, Forman D, Mason J, et al. (2000) Systematic review and economic evaluation of Helicobacter pylori eradication treatment for non-ulcer dyspepsia. Dyspepsia Review Group. BMJ 321: 659-664.

15. Laheij RJ van Rossum LG, Verbeek AL, Jansen JB (2003) Helicobacter pylori infection treatment of nonulcer dyspepsia: an analysis of metaanalyses. J Clin Gastroenterol 36: 315-320.

16. Issing WJ (2003) [Gastroesophageal reflux -- a common illness?]. Laryngorhinootologie 82: 118-122.

17. Labenz J Blum AL, Bayerdörffer E, Meining A, Stolte M, et al. (1997) Curing Helicobacter pylori infection in patients with duodenal ulcer may provoke reflux esophagitis. Gastroenterology 112: 1442-1447.

18. Sharma P Vakil N (2003) Review article: Helicobacter pylori and reflux disease. Aliment Pharmacol Ther 17: 297-305.

19. Vakil N (2003) Gastroesophageal reflux disease and Helicobacter pylori infection. Rev Gastroenterol Disord 3: 1-7.

20. Mesihovi ̈̈ R, Vucelï̈ B, BratoviÄ I, GribajceviÄ M, Selak I (2002) [Effect of eradication of Helicobacter pylori infection on endoscopic findings and symptoms of gastroesophageal reflux]. Med Arh 56: 201-206.

21. Ikeda S, Tamamuro T, Hamashima C, Asaka M (2001) Evaluation of the cost-effectiveness of Helicobacter pylori eradication triple therapy vs. conventional therapy for ulcers in Japan. Aliment Pharmacol Ther 15: 1777-1785. 
Citation: Nasrat AM, Nasrat SAM, Nasrat RM, Nasrat MM (2015) An Alternate Natural Remedy for Symptomatic Relief of Helicobacter pylori Dyspepsia. Gen Med (Los Angel) 3: 200. doi:10.4172/2327-5146.1000200

Page 5 of 5

22. Mason J, Axon AT, Forman D, Duffett S, Drummond M, et al. (2002) The cost-effectiveness of population Helicobacter pylori screening and treatment: a Markov model using economic data from a randomized controlled trial. Aliment Pharmacol Ther 16: 559-568.

23. Breuer T, Graham DY (1999) Costs of diagnosis and treatment of Helicobacter pylori infection: when does choosing the treatment regimen based on susceptibility testing become cost effective? Am J Gastroenterol 94: 725-729.

24. Wang Q, Jin PH, Lin GW, Xu SR, Chen J (2003) [Cost-effectiveness of Helicobacter pylori screening to prevent gastric cancer: Markov decision analysis]. Zhonghua Liu Xing Bing Xue Za Zhi 24: 135-139.

25. Moayyedi P, Axon AT (1998) Is there a rationale for eradication of Helicobacter pylori? Cost-benefit: the case for. Br Med Bull 54: 243-250.

26. Groeneveld PW, Lieu TA, Fendrick AM, Hurley LB, Ackerson LM, et al. (2001) Quality of life measurement clarifies the cost-effectiveness of Helicobacter pylori eradication in peptic ulcer disease and uninvestigated dyspepsia. Am J Gastroenterol 96: 338-347.

27. Ge Z (2002) Potential of fumarate reductase as a novel therapeutic target in Helicobacter pylori infection. Expert Opin Ther Targets 6: 135-146.

28. Baron S (2000) medical microbiology. Churchill Livingstone 4: 346.

29. Duggan AE Tolley K, Hawkey CJ, Logan RF (1998) Varying efficacy of Helicobacter pylori eradication regimens: cost effectiveness study using a decision analysis model. BMJ 316: 1648-1654.

30. Ben Ammar A, Cheikh I, Ouerghi H, Chaabouni H, Kchaou M, et al. (2002) [Prevalence of Helicobacter pylori infection in duodenal ulcer. Data of a prospective study apropos of 78 NSAID-negative patients with duodenal ulcer]. Tunis Med 80: 599-604.

31. Zentilin P, Iiritano E, Vignale C, Bilardi C, Mele MR, et al. (2003) Helicobacter pylori infection is not involved in the pathogenesis of either erosive or non-erosive gastro-oesophageal reflux disease. Aliment Pharmacol Ther 17: 1057-1064.

32. Volk WA, Gebhardt BM, Hammarskjold M-L (1996) Essential of Medical Microbiology. Lippincott Raven 5: 377.

33. McPhee SJ, Lingappa VR, Ganong WF (1996) Pathophysiology of Disease, An introduction to Clinical Medicine. Lange Medical Books / McGraw Hill 4: 361.

34. Cotran RS, Kumar V, Collins T Robins (1999) Pathologic Basis of Disease. WB Saunders Company 6: 790.

35. Sleigh JD, Timbury MC (1998) Notes on Medical Microbiology. Churchill Livingstone 5: 232.
36. Midolo PD, Lambert JR, Hull R (1995) In vitro inhibition of Helicobacter pylori NCTC 11637 by organic acids and lactic acid bacteria. J Appl Bacteriol 79: 475-479.

37. Vázquez FJ (1999) [Rosacea, vinegar and lemon, dysuria and Helicobacter pylori]. Medicina (B Aires) 59: 469-470.

38. Mendz GL, Hazell SL, Burns BP (1993) Glucose utilization and lactate production by Helicobacter pylori. J Gen Microbiol 139: 3023-3028.

39. Mendz GL, Hazell SL (1993) Fumarate catabolism in Helicobacter pylori. Biochem Mol Biol Int 31: 325-332.

40. Mendz GL, Hazell SL, van Gorkom L (1994) Pyruvate metabolism in Helicobacter pylori. Arch Microbiol 162: 187-192.

41. Hughes NJ, Clayton CL, Chalk PA, Kelly DJ (1998) Helicobacter pylori porCDAB and oorDABC genes encode distinct pyruvate:flavodoxin and 2-oxoglutarate:acceptor oxidoreductases which mediate electron transport to NADP. J Bacteriol 180: 1119-1128.

42. Berg JM, Tymoczko JL, Stryer L (2002) Biochemistry. WH Freeman and Company 5: 480.

43. Mendz GL, Ball GE, Meek DJ (1997) Pyruvate metabolism in Campylobacter spp. Biochim Biophys Acta 1334: 291-302.

44. Phull PS, Halliday D, Price AB, Jacyna MR (1996) Absence of dyspeptic symptoms as a test of Helicobacter pylori eradication. BMJ 312: 349-350.

45. Gené E, Calvet X, Azagra R (2000) Diagnosis of Helicobacter pylori after triple therapy in uncomplicated duodenal ulcers--a cost-effectiveness analysis. Aliment Pharmacol Ther 14: 433-442.

46. Gürbüz AK, Ozel AM, Yazgan Y, Celik M, Yildirim S (2003) Oral colonization of Helicobacter pylori: risk factors and response to eradication therapy. South Med J 96: 244-247.

47. Makino SI, Cheun HI, Tabuchi H, Shirahata T (2000) Antibacterial activity of chaff vinegar and its practical application. J Vet Med Sci 62: 893-895

48. Debevere J, Devlieghere F, van Sprundel P, De Meulenaer B (2001) Influence of acetate and $\mathrm{CO} 2$ on the TMAO-reduction reaction by Shewanella baltica. Int J Food Microbiol 68: 115-123.

49. Cirak MY, Ozdek A, Yilmaz D, Bayiz U, Samim E, et al. (2003) Detection of Helicobacter pylori and its CagA gene in tonsil and adenoid tissues by PCR. Arch Otolaryngol Head Neck Surg 129: 1225-1229.

50. Nasrat AM (2009) The world misconception and misbehavior towards Helicobacter pylori is leading to major spread of illness. The 7th AntiAging Medicine World Congress, Monte-Carlo, Monaco. 